MANTOVANI, J.R.; FERREIRA, M.E.; CRUZ, M.C.P.; CHIBA, M.K.; BRAZ, L.T. Calagem e adubação com vermicomposto de lixo urbano na produção e nos teores de metais pesados em alface. Horticultura Brasileira, Brasília, v. 21, n. 3, p. 494-500, julho-setembro 2003.

\title{
Calagem e adubação com vermicomposto de lixo urbano na produção e nos teores de metais pesados em alface
}

\author{
José Ricardo Mantovani ${ }^{1,4}$; Manoel Evaristo Ferreira ${ }^{1}$; Mara Cristina Pessôa da Cruz ${ }^{1,3}$; Márcio Koiti \\ Chiba $^{1,3}$; Leila Trevizan Braz ${ }^{2}$ \\ ${ }^{1}$ UNESP, Depto. Solos e Adubos, Via de Acesso Prof. Paulo Donato Castellane s/nº 14884-900 Jaboticabal-SP; ${ }^{2}$ Depto. Produção \\ Vegetal; ${ }^{3 B}$ Bolsista FAPESP; e-mail:jrmantov@intercanal.com.br
}

\section{RESUMO}

Foram realizados dois experimentos em casa de vegetação para avaliar o efeito da adição de um vermicomposto oriundo de lixo urbano e da calagem na matéria seca e na concentração de metais pesados na parte aérea de plantas de alface cv. Mesa 659. Em um dos ensaios, foi usado um Latossolo Vermelho distroférrico e, em outro, um Argissolo Vermelho-Amarelo eutrófico. O delineamento experimental de cada experimento foi em blocos ao acaso, em esquema fatorial $5 \times 5$, com quatro repetições, combinando-se calagem para elevar a saturação por bases a $40 ; 50 ; 60 ; 70$ e $80 \%$, e o equivalente a $0 ; 25 ; 50 ; 75$ e $100 \mathrm{t} \mathrm{ha}^{-1}$ de vermicomposto. Uma única aplicação de vermicomposto de lixo urbano, em doses acima de $50 \mathrm{t}$ ha $^{-1}$, limitou a produção de alface nos dois tipos de solos. Mesmo estas doses que restringiram a produção da alface, não a tornaram imprópria para consumo humano do ponto de vista da concentração de metais pesados.

\begin{abstract}
Liming and urban waste vermicompost effects on production and heavy metals concentration of lettuce

The effect of urban waste vermicompost over dry matter and heavy metal concentration in lettuce tops, was evaluated in two greenhouse experiments, one with an Oxissol and another an Alfissol. The experiments followed a completely randomized design combining five liming levels, to elevate the degree of base saturation to $40 ; 50 ; 60 ; 70$ and $80 \%$, with five vermicompost rates of $0 ; 25$; 50; 75 and $100 \mathrm{tha}^{-1}$, with four replicates. The use of urban waste vermicompost in higher rates than $50 \mathrm{t} \mathrm{ha}^{-1}$ limited the lettuce yield in both soils. Even at these rates, however, the lettuce did not become inappropriate as food from the point of view of heavy metal contamination.
\end{abstract}

Keywords: Lactuca sativa, organic manure, $\mathrm{pH}$.

Palavras-chave: Lactuca sativa, adubação orgânica, $\mathrm{pH}$.

(Recebido para publicação em 08 de maio de 2002 e aceito em 19 de maio de 2003)

$\mathrm{O}$ acúmulo de metais pesados em plantas depende de fatores como espécie, cultivar, órgão ou parte estudada. Segundo Simeoni et al. (1984), cereais, gramíneas, legumes e olerícolas tuberosas tendem a acumular menos metais do que plantas folhosas de crescimento rápido, como a alface.

Algumas características químicas do solo também influenciam na absorção de metais pesados pelas plantas, entre as quais, o $\mathrm{pH}$ desempenha papel fundamental. Albasel \& Cottenie (1985) verificaram que o aumento do $\mathrm{pH}$ do solo, devido à calagem, reduziu drasticamente a disponibilidade e, consequentemente, a absorção de chumbo, níquel e zinco por plantas de azevém e de cevada. Hooda \& Alloway (1996) observaram que a elevação do $\mathrm{pH}$, pela calagem, em solos de diferentes texturas, proporcionou decréscimo na concentração de cádmio, cobre, níquel, chumbo e zinco em cenoura e em espinafre.

$\mathrm{Na}$ reciclagem do lixo urbano, a compostagem e depois a vermicom- postagem da fração orgânica levam à produção de adubos orgânicos composto e vermicomposto, respectivamente. O vermicomposto é um produto de melhor qualidade, de maior aceitação e valor comercial. Segundo Berton \& Valadares (1991) e Egreja Filho (1993), duas características desses insumos são a ausência de microorganismos patogênicos e a presença de quantidades variáveis de metais pesados, como cádmio, níquel, chumbo, cobre, ferro, manganês e zinco. Por essa última característica, o uso agrícola de composto e de vermicomposto deve ser acompanhado, de maneira que se tenha controle das quantidades que podem ser acumuladas pelas plantas sem risco à saúde humana.

Petruzelli et al. (1989), em ensaio de campo, avaliaram o efeito da aplicação de $30 \mathrm{t} \mathrm{ha}^{-1}$ ano $^{-1}$ de composto de lixo, durante quatro anos, na cultura do milho. Constataram que o teor de cádmio, zinco e cobre nos grãos teve um aumento significativo em relação à tes- temunha apenas no terceiro e quarto cultivos, enquanto o teor de outros metais, como o níquel e o chumbo, não sofreram variações significativas no transcorrer do experimento. Alves et al. (1999), na ausência de adubação química, verificaram que, com a adição de composto de lixo, houve aumento da produção de matéria seca e das quantidades acumuladas de ferro, manganês e zinco na parte aérea de plantas de sorgo.

Em relação às olerícolas, Costa et al. (1994) verificaram que, em solos com acidez elevada e fertilidade baixa, houve aumento da produção de matéria seca de alface até a dose estimada de cerca de 20 tha $^{-1}$ de composto de lixo urbano adicionada a um solo argiloso, enquanto que em solo arenoso houve diminuição na produção. Quanto à concentração de metais, foram observados aumentos significativos nos teores de zinco, cobre, cádmio e chumbo na parte aérea das plantas, sendo que para o cobre, os teores foram considerados fitotóxicos. Num experimento de campo, em dois 
cultivos sucessivos de alface, Costa $e t$ al. (2001) obtiveram aumento linear na produção de matéria fresca da hortaliça, aumento significativo nos teores de zinco da parte aérea e nenhum efeito nos de cobre, níquel e chumbo, com a aplicação de composto de lixo urbano.

O presente trabalho teve como objetivo avaliar o efeito da adubação com vermicomposto de lixo urbano e da calagem na produção de matéria seca e na concentração de cádmio, níquel, chumbo, cobre, ferro, manganês e zinco da parte aérea de alface.

\section{MATERIAL E MÉTODOS}

Em casa de vegetação, foram realizados dois experimentos em vasos, empregando-se, no primeiro (abril a julho de 1997), um solo de textura argilosa e, no segundo (abril a julho de 1999), um solo de textura arenosa. Os solos foram coletados na camada arável $(0-20 \mathrm{~cm})$, respectivamente, de um Latossolo Vermelho distroférrico (LVdf) e de um Argissolo Vermelho-Amarelo eutrófico (PVAe). Foi feita caracterização química de rotina (Raij et al., 1987) e análise textural (Camargo et al., 1986). Os resultados obtidos para o LVdf e para o PVAe foram, respectivamente: $\mathrm{P}$ resina $=10$ e $16 \mathrm{mg} \mathrm{dm}^{-3}$; M.O. $=40$ e $10 \mathrm{~g}$ $\mathrm{dm}^{-3} ; \mathrm{pH} \mathrm{CaCl}_{2}=4,6$ e 4,$0 ; \mathrm{K}^{+}=1,8 \mathrm{e}$ $1,5 \mathrm{mmol} \mathrm{dm}^{-3} ; \mathrm{Ca}^{2+}=15$ e $4 \mathrm{mmol} \mathrm{dm}^{-3}$; $\mathrm{Mg}^{2+}=9$ e 2 mmol $_{\mathrm{c}} \mathrm{dm}^{-3} ; \mathrm{H}+\mathrm{Al}=58 \mathrm{e}$ $28 \mathrm{mmol} \mathrm{dm}_{\mathrm{c}}^{-3} ; \mathrm{SB}=26$ e $8 \mathrm{mmol} \mathrm{dm}_{\mathrm{c}}^{-3}$; $\mathrm{CTC}=84$ e $36 \mathrm{mmol} \mathrm{dm}_{\mathrm{c}}^{-3} ; \mathrm{V} \%=31 \mathrm{e}$ $21 ;$ argila $=646 \mathrm{e}^{2} \mathrm{~g} \mathrm{~kg}^{-1} ;$ silte $=247 \mathrm{e}$ $90 \mathrm{~g} \mathrm{~kg}^{-1}$; e areia $=107$ e $840 \mathrm{~g} \mathrm{~kg}^{-1}$.

$\mathrm{O}$ vermicomposto de lixo urbano utilizado, proveniente da ex-Estação Experimental da Companhia de Tecnologia de Saneamento Ambiental (CETESB), Novo Horizonte (SP), foi analisado conforme descrito em Kiehl (1985) e apresentou os seguintes teores de metais pesados, em $\mathrm{mg} \mathrm{kg}^{-1}$, base seca: $\mathrm{Cd}<1 ; \mathrm{Ni}=18 ; \mathrm{Pb}=122 ; \mathrm{Cu}=$ $197 ; \mathrm{Fe}=32000 ; \mathrm{Mn}=272 \mathrm{e} \mathrm{Zn}=455$.

Em cada experimento, foi empregado esquema fatorial $5 \times 5$, em delineamento em blocos ao acaso, com quatro repetições. Os tratamentos consistiram na combinação de cinco doses de corretivos da acidez e cinco doses de vermicomposto de lixo urbano. As do-

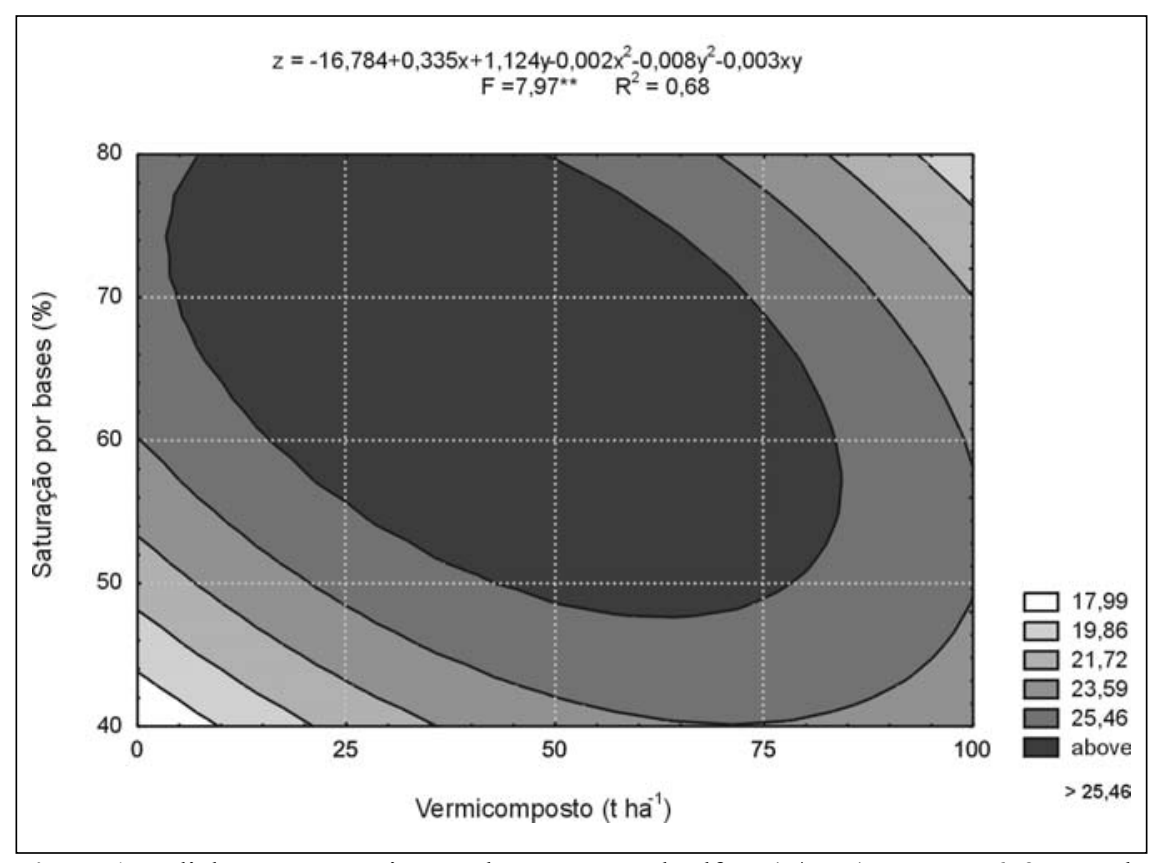

Figura 1. Isolinhas para matéria seca da parte aérea de alface (g/vaso) cv. Mesa 659, em solo argiloso em função de vermicomposto de lixo urbano e calagem. Jaboticabal, UNESP, 1997.

ses de corretivos da acidez foram estimadas para se obter índices de saturação por bases (V\%) iguais a 40; 50; 60; $70 \mathrm{e}$ 80, a relação Ca:Mg empregada foi igual a 4:1 para o solo argiloso e 2:1 para o arenoso, e os produtos utilizados foram $\mathrm{CaCO}_{3}$ e $4 \mathrm{MgCO}_{3} \cdot \mathrm{Mg}(\mathrm{OH})_{2} .5 \mathrm{H}_{2} \mathrm{O}$ p.a. As doses de vermicomposto adicionadas foram correspondentes a $0 ; 25 ; 50 ; 75$ e $100 \mathrm{t} \mathrm{ha}^{-1}$, com base no peso seco.

Os corretivos e o vermicomposto foram misturados, a seco, a porções de $5,5 \mathrm{dm}^{3}$ de solo, de acordo com cada tratamento, as quais foram transferidas para vasos de alumínio com capacidade para 5,8 L. O solo foi umedecido com água deionizada a $60 \%$ da capacidade de retenção e submetido a incubação por 40 dias. Aos 30 dias de incubação, foi feita adubação mineral de maneira a se ter, em mg dm${ }^{-3}$ : 120 de P; 20 de S; 0,5 de B; 1,25 de $\mathrm{Cu}$; 3,0 de $\mathrm{Mn} ; 0,02$ de Mo; e 2,5 de Zn, em ambos os solos, além de 36 de $\mathrm{N}$ e 150 de $\mathrm{K}$ no solo argiloso, e de 80 de $\mathrm{N}$ e 50 de $\mathrm{K}$ no solo arenoso. Foram usadas soluções preparadas a partir dos sais (p.a.): $\mathrm{NH}_{4} \mathrm{H}_{2} \mathrm{PO}_{4}$; $\mathrm{KNO}_{3} ; \mathrm{KH}_{2} \mathrm{PO}_{4} ; \mathrm{K}_{2} \mathrm{SO}_{4} ; \mathrm{H}_{3} \mathrm{BO}_{3}$; $\mathrm{CuSO}_{4} .5 \mathrm{H}_{2} \mathrm{O} ; \quad \mathrm{MnCl}_{2} .4 \mathrm{H}_{2} \mathrm{O}$; $\left(\mathrm{NH}_{4}\right)_{6} \mathrm{Mo}_{7} \mathrm{O}_{24} \cdot 4 \mathrm{H}_{2} \mathrm{O} ; \mathrm{ZnSO}_{4} \cdot 7 \mathrm{H}_{2} \mathrm{O}$.

Ao término da incubação, o solo foi seco ao ar e amostrado. Porções de 5 $\mathrm{dm}^{3}$ de solo foram devolvidas para os vasos e reumedecidas a $60 \%$ da capacidade de retenção. Em seguida, transplantou-se para cada vaso uma muda de alface (Lactuca sativa L.) do grupo americana, cultivar Mesa 659.

Foram feitas quatro adubações de cobertura de $15 \mathrm{mg} \mathrm{dm}^{-3}$ de $\mathrm{N}$, como $\mathrm{NH}_{4} \mathrm{NO}_{3}$, no solo argiloso, e de $18 \mathrm{mg}$ $\mathrm{dm}^{-3}$ de $\mathrm{N}$ mais $50 \mathrm{mg} \mathrm{dm}^{-3} \mathrm{de} \mathrm{K}$, como $\mathrm{KNO}_{3}$, no solo arenoso.

A colheita foi realizada 47 dias após o transplantio, cortando-se as plantas rente à superfície do solo de cada vaso. Avaliou-se a matéria seca e, em extrato de digestão nítrico-perclórica, determinaram-se os teores de cádmio, níquel, chumbo, cobre, ferro, manganês e zinco por espectrofotometria de absorção atômica (Bataglia et al., 1983).

Os resultados obtidos foram submetidos à análise de variância pelo Teste F, e o efeito de doses foi avaliado por meio de regressão polinomial.

\section{RESULTADOS E DISCUSSÃO}

$\mathrm{O}$ vermicomposto e a calagem afetaram significativamente a produção de matéria seca de alface em ambos os solos, com efeito da interação dos dois fatores apenas no LVdf (Tabelas 1 e 2). No LVdf verificou-se que, para valores

\section{Produção de matéria seca}


Tabela 1. Matéria seca e teor de metais pesados na parte aérea de alface cv. Mesa 659 cultivada em solo argiloso, LVdf. Média de quatro repetições. Jaboticabal, UNESP, 1997.

\begin{tabular}{|c|c|c|c|c|c|c|c|}
\hline \multirow{2}{*}{ Trat. } & \multirow{2}{*}{$\begin{array}{c}\text { MS } \\
\text { g/vaso }\end{array}$} & Cd & $\mathrm{Ni}$ & $\mathrm{Cu}$ & $\mathrm{Fe}$ & $\mathbf{M n}$ & $\mathrm{Zn}$ \\
\hline & & \multicolumn{6}{|c|}{$\mathrm{mg} \mathrm{kg}^{-1}$} \\
\hline $\mathrm{VM}_{0} \mathrm{C}_{0}(1)$ & 14,44 & 0,11 & 0,65 & 5 & 63 & 216 & 38 \\
\hline $\mathrm{VM}_{1} \mathrm{C}_{0}$ & 19,48 & 0,12 & 0,53 & 5 & 66 & 116 & 41 \\
\hline $\mathrm{VM}_{2} \mathrm{C}_{0}$ & 21,52 & 0,13 & 0,87 & 7 & 61 & 90 & 56 \\
\hline $\mathrm{VM}_{3} \mathrm{C}_{0}$ & 24,26 & 0,14 & 0,88 & 6 & 75 & 70 & 56 \\
\hline $\mathrm{VM}_{4} \mathrm{C}_{0}$ & 24,88 & 0,14 & 1,04 & 6 & 59 & 61 & 55 \\
\hline $\mathrm{VM}_{0} \mathrm{C}_{1}$ & 20,96 & 0,08 & 0,50 & 6 & 71 & 123 & 40 \\
\hline $\mathrm{VM}_{1} \mathrm{C}_{1}$ & 25,34 & 0,11 & 0,56 & 6 & 79 & 81 & 41 \\
\hline $\mathrm{VM}_{2} \mathrm{C}_{1}$ & 25,12 & 0,12 & 0,80 & 6 & 61 & 67 & 48 \\
\hline $\mathrm{VM}_{3} \mathrm{C}_{1}$ & 26,11 & 0,13 & 0,80 & 6 & 67 & 55 & 48 \\
\hline $\mathrm{VM}_{4} \mathrm{C}_{1}$ & 23,18 & 0,14 & 1,05 & 7 & 63 & 60 & 59 \\
\hline $\mathrm{VM}_{0} \mathrm{C}_{2}$ & 28,16 & 0,08 & 0,69 & 5 & 53 & 71 & 24 \\
\hline $\mathrm{VM}_{1} \mathrm{C}_{2}$ & 26,63 & 0,11 & 0,70 & 5 & 68 & 66 & 38 \\
\hline $\mathrm{VM}_{2} \mathrm{C}_{2}$ & 26,87 & 0,12 & 0,69 & 6 & 60 & 57 & 43 \\
\hline $\mathrm{VM}_{3} \mathrm{C}_{2}$ & 27,66 & 0,12 & 0,85 & 6 & 60 & 54 & 45 \\
\hline $\mathrm{VM}_{4} \mathrm{C}_{2}$ & 18,77 & 0,14 & 1,10 & 8 & 89 & 53 & 59 \\
\hline $\mathrm{VM}_{0} \mathrm{C}_{3}$ & 24,60 & 0,06 & 0,74 & 5 & 67 & 63 & 27 \\
\hline $\mathrm{VM}_{1} \mathrm{C}_{3}$ & 24,76 & 0,10 & 0,74 & 5 & 55 & 63 & 39 \\
\hline $\mathrm{VM}_{2} \mathrm{C}_{3}$ & 26,25 & 0,10 & 0,77 & 6 & 59 & 56 & 45 \\
\hline $\mathrm{VM}_{3} \mathrm{C}_{3}$ & 27,01 & 0,10 & 0,91 & 6 & 60 & 46 & 45 \\
\hline $\mathrm{VM}_{4} \mathrm{C}_{3}$ & 20,40 & 0,13 & 0,87 & 7 & 66 & 47 & 52 \\
\hline $\mathrm{VM}_{0} \mathrm{C}_{4}$ & 23,85 & 0,05 & 0,62 & 5 & 61 & 54 & 27 \\
\hline $\mathrm{VM}_{1} \mathrm{C}_{4}$ & 24,10 & 0,10 & 0,65 & 7 & 60 & 53 & 40 \\
\hline $\mathrm{VM}_{2} \mathrm{C}_{4}$ & 27,86 & 0,12 & 0,64 & 7 & 61 & 53 & 42 \\
\hline $\mathrm{VM}_{3} \mathrm{C}_{4}$ & 22,76 & 0,14 & 0,69 & 7 & 75 & 57 & 52 \\
\hline \multirow[t]{2}{*}{$\mathrm{VM}_{4} \mathrm{C}_{4}$} & 20,45 & 0,14 & 0,73 & 7 & 60 & 54 & 49 \\
\hline & \multicolumn{7}{|c|}{ Significância do teste $\mathrm{F}^{(2)}$} \\
\hline VM & ** & ** & ** & $* *$ & ns & ** & ** \\
\hline C & ** & ** & * & * & ns & ** & ** \\
\hline $\mathrm{VMxC}$ & ** & ns & ns & ns & ns & ** & * \\
\hline $\mathrm{CV}(\%)$ & 12 & 14 & 21 & 13 & 19 & 14 & 13 \\
\hline
\end{tabular}

(1)em que: $\mathrm{VM}_{0}, \mathrm{VM}_{1}, \mathrm{VM}_{2}, \mathrm{VM}_{3}$ e $\mathrm{VM}_{4}$ correspondem, respectivamente, a $0 ; 25 ; 50 ; 75$ e $100 \mathrm{t} /$ ha de vermicomposto e $\mathrm{C}_{0}, \mathrm{C}_{1}, \mathrm{C}_{2}, \mathrm{C}_{3}$ e $\mathrm{C}_{4}$, a adição de corretivos para elevar a saturação por bases a 40;50;60; 70 e $80 \%$.

(2) $\mathrm{ns},{ }^{*} \mathrm{e} * *$ : não significativo e significativo à $5 \%$ e $1 \%$ de probabilidade, respectivamente.

de saturação por bases desejados menores do que $60 \%$, houve aumento de produção de matéria seca com aplicação de até cerca de $50 \mathrm{t} \mathrm{ha}^{-1}$ de vermicomposto de lixo urbano (Figura 1). Para valores de $\mathrm{V} \%$ maiores do que 70 , ocorreu decréscimo de produção com a adição de doses maiores do que $75 \mathrm{t} \mathrm{ha}^{-1}$ do vermicomposto. Estima-se que a máxima produção poderá ser obtida combinando-se doses de vermicomposto en- tre 15 e $75 \mathrm{t} \mathrm{ha}^{-1}$ e saturação por bases desejada entre 50 e $70 \%$.

No PVAe, houve efeito quadrático do vermicomposto $(\mathrm{x})$ na produção de matéria seca de alface (y), ocorrendo decréscimo na produção em doses de vermicomposto acima de $55 \mathrm{t} \mathrm{ha}^{-1}(\mathrm{y}=$ $-0,0013 \mathrm{x}^{2}+0,1435 \mathrm{x}+29,044, \mathrm{R}^{2}=$ $0,918 * *)$. Essa diminuição de produção, de 33,00 para $30,39 \mathrm{~g} /$ vaso $(8 \%)$, foi menor do que a ocorrida no LVdf, no qual foi de 25,46 para 19,86 g/vaso (22\%). A máxima produção de matéria seca da parte aérea de alface no PVAe, estimada para as condições do experimento, seria obtida com a adição de 55 $\mathrm{t} \mathrm{ha}^{-1}$ de vermicomposto de lixo. Costa et al. (1994) e Santos (1995), em solo argiloso, também observaram diminuição na produção de matéria seca de alface, com a aplicação de doses de composto de lixo maiores do que $60 \mathrm{t} \mathrm{ha}^{-1} \mathrm{e}$ 
Tabela 2. Matéria seca e teor de metais pesados na parte aérea de alface cv. Mesa 659 cultivada em solo arenoso, PVAe. Média de quatro repetições. Jaboticabal, UNESP, 1997.

\begin{tabular}{|c|c|c|c|c|c|c|c|c|}
\hline \multirow{2}{*}{ Trat. } & \multirow{2}{*}{ MSg/vaso - } & $\mathrm{Cd}$ & $\mathrm{Ni}$ & $\mathrm{Pb}$ & $\mathrm{Cu}$ & $\mathrm{Fe}$ & $\mathrm{Mn}$ & $\mathrm{Zn}$ \\
\hline & & \multicolumn{7}{|c|}{$\mathrm{mg} \mathrm{kg}^{-1}$} \\
\hline $\mathrm{VM}_{0} \mathrm{C}_{0}(1)$ & 24,01 & 0,26 & 1,66 & 1,95 & 4 & 79 & 632 & 79 \\
\hline $\mathrm{VM}_{1} \mathrm{C}_{0}$ & 29,24 & 0,24 & 1,21 & 1,04 & 5 & 79 & 207 & 74 \\
\hline $\mathrm{VM}_{2} \mathrm{C}_{0}$ & 33,16 & 0,22 & 1,08 & 1,21 & 5 & 71 & 138 & 69 \\
\hline $\mathrm{VM}_{3} \mathrm{C}_{0}$ & 31,98 & 0,26 & 0,56 & 1,50 & 6 & 70 & 121 & 69 \\
\hline $\mathrm{VM}_{4} \mathrm{C}_{0}$ & 26,77 & 0,44 & 1,08 & 1,88 & 7 & 93 & 113 & 76 \\
\hline $\mathrm{VM}_{0} \mathrm{C}_{1}$ & 26,91 & 0,21 & 1,31 & 1,80 & 4 & 71 & 336 & 66 \\
\hline $\mathrm{VM}_{1} \mathrm{C}_{1}$ & 31,75 & 0,18 & 0,92 & 1,91 & 5 & 67 & 146 & 63 \\
\hline $\mathrm{VM}_{2} \mathrm{C}_{1}$ & 31,39 & 0,21 & 0,83 & 1,37 & 5 & 65 & 116 & 61 \\
\hline $\mathrm{VM}_{3} \mathrm{C}_{1}$ & 32,8 & 0,33 & 0,83 & 1,92 & 6 & 64 & 105 & 65 \\
\hline $\mathrm{VM}_{4} \mathrm{C}_{1}$ & 29,98 & 0,27 & 0,82 & 1,51 & 6 & 60 & 104 & 63 \\
\hline $\mathrm{VM}_{0} \mathrm{C}_{2}$ & 30,91 & 0,11 & 0,81 & 0,89 & 4 & 78 & 184 & 60 \\
\hline $\mathrm{VM}_{1} \mathrm{C}_{2}$ & 33,43 & 0,14 & 0,89 & 1,18 & 4 & 71 & 126 & 62 \\
\hline $\mathrm{VM}_{2} \mathrm{C}_{2}$ & 33,99 & 0,11 & 0,93 & 1,08 & 5 & 62 & 103 & 54 \\
\hline $\mathrm{VM}_{3} \mathrm{C}_{2}$ & 33,58 & 0,13 & 0,82 & 0,91 & 5 & 65 & 94 & 55 \\
\hline $\mathrm{VM}_{4} \mathrm{C}_{2}$ & 32,46 & 0,20 & 0,54 & 1,02 & 6 & 67 & 90 & 55 \\
\hline $\mathrm{VM}_{0} \mathrm{C}_{3}$ & 32,26 & 0,14 & 0,64 & 1,11 & 4 & 57 & 165 & 51 \\
\hline $\mathrm{VM}_{1} \mathrm{C}_{3}$ & 30,87 & 0,14 & 0,84 & 0,74 & 5 & 57 & 119 & 53 \\
\hline $\mathrm{VM}_{2} \mathrm{C}_{3}$ & 33,17 & 0,13 & 0,51 & 0,81 & 5 & 56 & 115 & 52 \\
\hline $\mathrm{VM}_{3} \mathrm{C}_{3}$ & 34,38 & 0,18 & 0,74 & 1,23 & 7 & 68 & 115 & 60 \\
\hline $\mathrm{VM}_{4} \mathrm{C}_{3}$ & 32,23 & 0,16 & 0,42 & 0,58 & 6 & 56 & 110 & 52 \\
\hline $\mathrm{VM}_{0} \mathrm{C}_{4}$ & 32,27 & 0,13 & 0,71 & 1,12 & 4 & 56 & 158 & 49 \\
\hline $\mathrm{VM}_{1} \mathrm{C}_{4}$ & 31,88 & 0,12 & 0,69 & 1,29 & 5 & 64 & 119 & 47 \\
\hline $\mathrm{VM}_{2} \mathrm{C}_{4}$ & 31,11 & 0,28 & 0,59 & 1,84 & 5 & 64 & 107 & 48 \\
\hline $\mathrm{VM}_{3} \mathrm{C}_{4}$ & 32,21 & 0,21 & 0,56 & 2,16 & 6 & 64 & 109 & 47 \\
\hline \multirow[t]{2}{*}{$\mathrm{VM}_{4} \mathrm{C}_{4}$} & 26,65 & 0,20 & 0,74 & 2,05 & 6 & 79 & 100 & 51 \\
\hline & \multicolumn{8}{|c|}{ Significância do teste $\mathrm{F}^{(2)}$} \\
\hline VM & ** & ** & ns & ns & $* *$ & ns & $* *$ & ns \\
\hline C & * & * & ** & ** & ns & $* *$ & $* *$ & $* *$ \\
\hline VMxC & $\mathrm{ns}$ & $\mathrm{ns}$ & ns & $\mathrm{ns}$ & ns & $\mathrm{ns}$ & ${ }^{* *}$ & ns \\
\hline CV (\%) & 12 & 51 & 46 & 54 & 15 & 19 & 11 & 13 \\
\hline
\end{tabular}

$35 \mathrm{t} \mathrm{ha}^{-1}$, respectivamente. Estes autores acreditam que o aumento da condutividade elétrica no solo pode ter sido uma das causas de redução de produção.

A calagem teve efeito quadrático na produção de matéria seca da parte aérea das plantas de alface no PVAe (Tabela 3 ), tendo a produção aumentado ao se efetuar calagem para elevar o V\% a até cerca de $65 \%$. Ainda, observou-se que a produção de matéria seca de alface no PVAe foi maior do que no LVdf. Essa diferença de produção, provavelmente, foi devida à variação na temperatura, nos dois anos de condução dos ensaios, pois os valores médios de temperatura mínima, média e máxima em Jaboticabal, durante a condução dos experimentos em 1997 e em 1999, foram de 12,$8 ; 18,5$ e $26,2^{\circ} \mathrm{C}$ e, 13,$6 ; 19,5$ e $27,7^{\circ} \mathrm{C}$, respectivamente.
A equação de regressão múltipla mostra que a produção de matéria seca (y) no LVdf foi afetada pelos teores de cobre e de manganês $(\mathrm{y}=40,529$ $1,839 \mathrm{Cu}-0,077 \mathrm{Mn}, \mathrm{R}^{2}=0,62 * *, \mathrm{~F}_{\mathrm{Cu}}=$ $\left.1,70, \mathrm{~F}_{\mathrm{Mn}}=34,89\right)$ e, no PVAe, pelos de ferro e de manganês $(\mathrm{y}=41,735$ $0,129 \mathrm{Fe}-0,012 \mathrm{Mn}, \mathrm{R}^{2}=0,63^{* *}, \mathrm{~F}_{\mathrm{Fe}}=$ $\left.23,08, \mathrm{~F}_{\mathrm{Mn}}=15,05\right)$. No solo argiloso, como indica o maior valor do teste $\mathrm{F}$ para manganês, a concentração desse 
Tabela 3. Equações de regressão expressando o efeito do vermicomposto (VM), da saturação por bases (V\%) e de ambos, na matéria seca (M.S.) e nos teores de cádmio, níquel, cobre, chumbo, ferro, zinco e manganês, em alface cv. Mesa 659. Jaboticabal, UNESP, 1997.

\begin{tabular}{|c|c|c|c|c|}
\hline Solo & $\begin{array}{c}\text { Variável } \\
\text { independente }\end{array}$ & $\begin{array}{c}\text { Variáveis } \\
\text { dependentes }\end{array}$ & Equação & $\mathbf{R}^{2}$ \\
\hline$\overline{L V d f}$ & VM & $\mathrm{Cd}$ & $y=-0,000005 x^{2}+0,0010 x+0,0790$ & $0,97^{* *}$ \\
\hline PVAe & VM & $\mathrm{Cd}$ & $y=0,0010 x+0,1550$ & $0,90 * *$ \\
\hline LVdf & VM & $\mathrm{Ni}$ & $y=0,0030 x+0,5950$ & $0,93^{* *}$ \\
\hline PVAe & VM & $\mathrm{Ni}$ & $y=-0,0030 x+0,9750$ & $0,86^{*}$ \\
\hline LVdf & VM & $\mathrm{Cu}$ & $y=0,0160 x+5,2890$ & $0,97^{* *}$ \\
\hline PVAe & VM & $\mathrm{Cu}$ & $y=0,0210 x+4,2330$ & $0,98^{* *}$ \\
\hline PVAe & $\mathrm{V} \%$ & M.S. & $y=-0,0065 x^{2}+0,8402 x+5,6111$ & $0,92^{* *}$ \\
\hline LVdf & $\mathrm{V} \%$ & $\mathrm{Cd}$ & $y=-0,00054 x+0,1456$ & $0,62^{* *}$ \\
\hline PVAe & V\% & $\mathrm{Cd}$ & $y=0,0002 x^{2}-0,0266 x+1,0443$ & $0,89^{* *}$ \\
\hline PVAe & V\% & $\mathrm{Ni}$ & $y=-0,0118 x+1,5276$ & $0,89^{* *}$ \\
\hline PVAe & $\mathrm{V} \%$ & $\mathrm{~Pb}$ & $y=0,0012 x^{2}-0,1502 x+5,7877$ & $0,42^{*}$ \\
\hline PVAe & $\mathrm{V} \%$ & $\mathrm{Fe}$ & $y=0,0185 x^{2}-2,549 x+150,03$ & $0,76^{*}$ \\
\hline PVAe & $\mathrm{V} \%$ & $\mathrm{Zn}$ & $y=0,0082 x^{2}-1,5887 x+123,46$ & $0,99^{* *}$ \\
\hline LVdf & VM & $\begin{array}{l}z=Z n \\
y=V \%\end{array}$ & $\begin{array}{l}z=70,810+0,288 x-1,107 y-0,001 x^{2}+ \\
0,007 y^{2}+0,001 x y\end{array}$ & $0,87^{* *}$ \\
\hline LVdf & VM & $\begin{array}{l}z=M n \\
y=V \%\end{array}$ & $\begin{array}{l}z=470,426-3,135 x-9,596 y+0,007 x^{2}+ \\
0,055 y^{2}+0,033 x y\end{array}$ & $0,87^{* *}$ \\
\hline PVAe & VM & $\begin{array}{l}z=M n \\
y=V \%\end{array}$ & $\begin{array}{l}z=1405,590-12,920 x-30,380 y+0,043 x^{2}+ \\
0,185 y^{2}+0,120 x y\end{array}$ & $0,77^{* *}$ \\
\hline
\end{tabular}

elemento na parte aérea das plantas teve maior influência na produção do que a de cobre. No solo arenoso, porém, o ferro e o manganês influenciaram a produção das plantas aproximadamente na mesma intensidade. Esses metais afetaram a produção das plantas nos dois tipos de solos, de forma linear e negativa. Dessa maneira, considerando-se os elementos em análise, o aumento de produção de matéria seca de 14,44 para $24,88 \mathrm{~g} /$ vaso $(72 \%)$, do tratamento $\mathrm{VM}_{0} \mathrm{C}_{0}$ para o $\mathrm{VM}_{4} \mathrm{C}_{0}$, no LVdf (Tabela 1), deve ter sido devido, especialmente, ao decréscimo da concentração de manganês na parte aérea das plantas.

Teores de metais pesados nas plantas: efeitos dos tratamentos

Os teores de quase todos os metais pesados nas plantas de alface sofreram mudanças significativas com os tratamentos aplicados (Tabelas 1 e 2). Os teores de chumbo nas plantas cultivadas no LVdf, entretanto, ficaram abaixo do limite de detecção, calculado, no caso, em 0,21 mg kg-1, de acordo com Tedesco et al. (1999), e por isso não estão sendo apresentados.

\section{a) no solo argiloso, $\mathrm{LVdf}$}

Observou-se efeito significativo do vermicomposto e da calagem nas concentrações de cádmio, níquel, cobre, manganês e zinco na parte aérea de alface, e a interação dos fatores foi significativa para manganês e zinco (Tabela 1). Nos casos em que houve efeito significativo de interação, foram feitos estudos por meio de regressões múltiplas. Vermicomposto e calagem não afetaram significativamente a concentração de ferro na parte aérea das plantas. Os teores de cádmio, níquel, cobre e zinco na parte aérea de alface aumentaram significativamente em função das doses de vermicomposto de lixo urbano (Tabela 3 ), tendo sido observado maior incremento para o zinco. Costa et al. (1994) e Costa et al. (1997) também observaram aumentos na concentração de cobre e zinco, em alface e em cenoura, com a adição de composto de lixo.

Em relação ao manganês, verificouse diminuição dos teores desse elemento na parte aérea de alface com o aumento das doses de vermicomposto de lixo urbano, sendo essa tendência mais acentuada para valores de saturação por bases inferiores a 50\% (Tabela 3 ). Apesar de o vermicomposto ser fornecedor de manganês, ele também provoca aumento de $\mathrm{pH}$, o que provavelmente levou à diminuição da disponibilidade desse micronutriente no solo e, consequentemente, ao decréscimo de sua absorção pelas plantas de alface. Alves et al. (1999), também verificaram decréscimo dos teores de manganês extraídos com DTPA no solo, com aplicação de composto de lixo.

O aumento da saturação por bases acarretou redução dos teores de zinco e de manganês na matéria seca de alface (Tabela 3). Para o manganês, tal efeito foi mais pronunciado em doses de vermicomposto menores do que $50 \mathrm{tha}^{-1}$.

Observou-se decréscimo linear da concentração de cádmio em alface, com a elevação do V\% (Tabela 3). Para os demais elementos, cobre, níquel e ferro, não foi verificada tendência definida com a calagem.

\section{b) no solo arenoso, PVAe}

No solo arenoso, o vermicomposto afetou significativamente a concentra- 
ção de cádmio, cobre e manganês em alface (Tabela 2). A calagem, por outro lado, afetou as concentrações de cádmio, níquel, chumbo, ferro, manganês e zinco, mas observou-se interação apenas para manganês. Não foi observado efeito significativo do vermicomposto nos teores de níquel, chumbo, ferro e zinco nas plantas. Para esses elementos, com exceção do níquel, também não foram constatadas tendências definidas com a aplicação desse adubo orgânico. Para o níquel, houve decréscimo de concentração com o aumento das doses de vermicomposto (Tabela 3). A aplicação de vermicomposto de lixo urbano acarretou aumento significativo nos teores de cádmio e cobre, na parte aérea de alface (Tabela 3). Em contrapartida, a concentração de manganês diminuiu com a adição desse insumo, especialmente nos tratamentos que receberam calagem para elevar o $\mathrm{V} \%$ a valores inferiores a 50 (Tabela 3).

Verifica-se, ainda, com as equações de regressão apresentadas na Tabela 3 , decréscimo dos teores de cádmio, níquel, chumbo, ferro e zinco na parte aérea das plantas com a elevação da saturação por bases. Esse decréscimo, também, foi verificado para manganês quando se aplicaram doses de vermicomposto menores do que $50 \mathrm{t} \mathrm{ha}^{-1}$ (Tabela 3). Resultados similares foram obtidos por Hooda \& Alloway (1996), que verificaram decréscimo na concentração de metais pesados em cenoura e em espinafre com o aumento do $\mathrm{pH}$. Os teores de cádmio, chumbo, manganês e zinco na parte aérea de alface, em solo arenoso (PVAe), foram maiores do que os encontrados naquelas cultivadas no LVdf. As concentrações dos demais elementos, níquel, cobre e ferro, foram, de maneira geral, similares na parte aérea das plantas de alface cultivadas nos dois tipos de solos.

Teores de metais pesados nas plantas: fitotoxicidade e adequação para consumo

Trani \& Raij (1997) definem os teores de cobre, ferro, manganês e zinco entre: 7-20; 50-150; 30-150; e 30-100 $\mathrm{mg} \mathrm{kg}^{-1}$, respectivamente, como adequados para folhas de alface recém-desenvolvidas, coletadas na metade do ciclo. As concentrações destes metais obser- vadas na parte aérea da alface cultivada no LVdf (Tabela 1) variaram de 5-8; de 53-89; de 46-216; e de 24-59 $\mathrm{mg} \mathrm{kg}^{-1}$; para $\mathrm{Cu}, \mathrm{Fe}, \mathrm{Mn}$ e $\mathrm{Zn}$, respectivamente. Na alface cultivada no PVAe (Tabela 2), variaram de 4-7; de 56-93; de 90-632; e de 47-79 $\mathrm{mg} \mathrm{kg}^{-1}$, respectivamente. Pelo exposto, a maioria dos teores desses elementos situa-se dentro dos limites apresentados por Trani \& Raij (1997). Gupta \& Gupta (1998) relatam como fitotóxicos, para a maioria das plantas, teores de cobre, manganês e zinco, entre 10-70; 400-7000; e 95-340 $\mathrm{mg} \mathrm{kg}^{-1}$, respectivamente; portanto, muito acima dos observados nesse experimento. Os teores de níquel ficaram bem abaixo da faixa considerada fitotóxica por Macnicol \& Beckett (1985), em folhas de alface, que é de 20-45 $\mathrm{mg} \mathrm{kg}^{-1}$ de Ni. Quanto ao chumbo, Boon \& Soltanpour (1992) observaram que teores de até 45 $\mathrm{mg} \mathrm{kg}{ }^{-1} \mathrm{de} \mathrm{Pb}$ na parte aérea de alface não provocaram quaisquer efeitos negativos na produção.

De acordo com Mesquita Filho et al. (2001), a legislação brasileira de alimentos especifica teores máximos, na matéria fresca, de 50; 30 e $1,0 \mathrm{mg} \mathrm{kg}^{-1} \mathrm{de}$ zinco, cobre e cádmio, respectivamente. Rodella \& Alcarde (2001) relatam que essa mesma legislação estabelece, para hortaliças in natura, teores de até $0,5 \mathrm{mg} \mathrm{kg}^{-1} \mathrm{de} \mathrm{Pb}$. Com base na informação de Furlani et al. (1978), de que a parte aérea de alface do tipo americana possui $950 \mathrm{~g} \mathrm{~kg}^{-1}$ de água, podem-se converter os dados das Tabelas 1 e 2 expressos em matéria seca, para matéria fresca. Desta forma, observa-se uma variação, em mg kg-1 de matéria fresca, de 1,2-4,0 para zinco, de 0,2-0,4 para cobre, de 0,003-0,02 para cádmio e de 0,002-0,11 para o chumbo, teores bem abaixo dos citados por Mesquita Filho et al. (2001) e por Rodella \& Alcarde (2001).

De acordo com os resultados obtidos, infere-se que a adubação com uma única aplicação de vermicomposto de lixo urbano, em doses acima de $50 \mathrm{tha}^{-1}$, limitou a produção de alface nos dois tipos de solos. Mesmo estas doses que restringiram a produção da alface, não a tornaram imprópria para consumo humano do ponto de vista da concentração de metais pesados.

\section{AGRADECIMENTOS}

Agradecemos à FAPESP e ao CNPq pelo financiamento e pelas bolsas de pesquisa e de iniciação científica que tornaram possível a execução do presente projeto.

\section{LITERATURA CITADA}

ALBASEL, N.; COTTENIE, A. Heavy metals uptake from contaminated soils as affected by peat, lime and chelates. Soil Science Society of America Journal, v. 49, p. 386-390, 1985.

ALVES, W.L.; MELO, W.J.; FERREIRA, M.E. Efeito do composto de lixo urbano em um solo arenoso e em plantas de sorgo. Revista Brasileira de Ciência do Solo, Viçosa, v. 23, p. 729-736, 1999.

BATAGLIA, O.C.; FURLANI, A.M.C.; TEIXEIRA, J.P.F.; FURLANI, P.R.; GALLO, J.R. Métodos de análise química de plantas. Campinas: Instituto Agronômico, 1983. 48 p. (Boletim Técnico, 78).

BERTON, R.S., VALADARES, J.M.A.S. Potencial agrícola do composto de lixo urbano no Estado de São Paulo. O Agronômico, Campinas, v. 43, p. 87-93, 1991.

BOON, D.Y.; SOLTANPOUR, P.N. Lead, cadmium and zinc contamination of Aspen Garden Soils and Vegetation. Journal of Environmental Quality, v. 21, p. 82-86, 1992.

CAMARGO, O.A.; MONIZ, A.C.; JORGE, J.A.; VALADARES, J.M.A.S. Métodos de análise química, mineralógica e física de solos do Instituto Agronômico de Campinas. Campinas: Instituto Agronômico, 1986. 94 p. (Boletim Técnico, 106). COSTA, C.A.; CASALI, V.W.D.; LOURES, E.G.; CECON P.R.; JORDÃO, C.P. Teor de metais pesados em alface (Lactuca sativa L.) adubada com composto orgânico de lixo urbano. Revista Ceres, Viçosa, v. 41, p. 629-640, 1994.

COSTA, C.A.; CASALI, V.W.D.; LOURES, E.G.; CECON P.R.; JORDÃO, C.P. Teor de zinco, cobre e cádmio em cenoura em função de doses crescentes de composto de lixo urbano. Horticultura Brasileira, Brasília, v. 15, p. 10-14, 1997.

COSTA, C.A.; CASALI, V.W.D.; RUIZ, H.A.; JORDÃO, C.P.; CECON, P.R. Teor de metais pesados e produção de alface adubada com composto de lixo urbano. Horticultura Brasileira, v. 19, p. 10-16, 2001.

EGREJA FILHO, F.B. Avaliação da ocorrência e distribuição química de metais pesados na compostagem do lixo domiciliar urbano. Viçosa: UFV, 1993. 176 p. (Tese doutorado)

FURLANI, A.M.C.; FURLANI, P.R.; BATAGLIA, O.C. Composição mineral de diversas hortaliças. Bragantia, Campinas, v. 37, p. $33-$ 44, 1978.

GUPTA, U.C.; GUPTA, S.C. Trace element toxicity relationship to crop production and livestock and human health: implications form manegement. Communications in Soil Science and Plant Analysis, v. 29, p. 1491-1522, 1998. 
HOODA, P.S.; ALLOWAY, B.J. The effect of liming on heavy metal concentrations in wheat, carrots and spinach grown on previously sludgeapplied soils. Journal of Agricultural Science, v. 127, p. 289-294, 1996.

KIEHL, E.J. Fertilizantes orgânicos. São Paulo Agronômica Ceres, 1985. 492 p.

MACNICOL, R.D.; BECKETT, P.H.T Critica tissue concentration of potentially toxic elements. Plant and Soil, v. 85, p. 107-129, 1985.

MESQUITA FILHO, M.V.; SOUZA, A.F.; FURLANI, P.R. Hortaliças de bulbo, tubérculo, raiz e fruto. In: FERREIRA, M.E.; CRUZ, M.C.P.; RAIJ, B.van; ABREU, C.A. (Ed.) Micronutrientes e elementos tóxicos na agricultura. Jaboticabal: CNPQ/FAPESP/POTAFOS, 2001. cap. 20, p. 511532.
PETRUZZELLI, G.; LUBRANO, L.; GUIDI, G. Uptake by corn and chemical extractability of heavy metals from a four years compost treated soil. Plant and Soil, v. 116, p. 23-27, 1989. RAIJ, B. Van; QUAGGIO, J.A.; CANTARELLA, H.; FERRIRA, M.E.; LOPES, A.S.; BATAGLIA, O.C. Análise química do solo para fins de fertilidade. Campinas: Fundação Cargill, 1987, 170 p. RODELLA, A.A.; ALCARDE, J.C. Legislação sobre micronutrientes e metais pesados. In: FERREIRA, M.E.; CRUZ, M.C.P.; RAIJ, B.; ABREU, C.A. (Ed.). Micronutrientes e elementos tóxicos na agricultura. Jaboticabal: CNPQ/ FAPESP/POTAFOS, 2001. cap. 22, p. 555-576.

SANTOS, I.C. Conteúdo de metais pesados, potássio e sódio e produção de cultivares de alface adubados com composto orgânico de lixo urbano. Viçosa: UFV, 1995. 89 p. (Tese doutorado).
SIMEONI, L.A.; BRABARICK, K.A.; SABEY, B.R. Effect of a small-scale composting of sewage sludge on heavy metal availability to plants. Journal Environmental Quality, v. 13, p. 264-268, 1984.

TEDESCO, M.J.; SILVA, L.M.C.; GIANELLO, C.; HIGA, R.H.; SILVA, F.C.; MASSRUHÁ, S.M.F.S. Infra-estrutura, geração e gerenciamento da informação laboratorial. In: SILVA, F.C. (org.) Manual de análises químicas de solos, plantas e fertilizantes. Brasília: Embrapa, 1999. cap. 7, p. 319-368.

TRANI, P.E.; RAIJ, B. van. Hortaliças. In: RAIJ, B.; CANTARELLA, H.; QUAGGIO, J.A.; FURLANI, A.M.C.(Ed.). Recomendações de adubação e calagem para o Estado de São Paulo. 2.ed. ver. atual. Campinas: Instituto Agronômico/ Fundação IAC, 1997. cap. 18, p. 157-185. (Boletim Técnico, 100). 